\title{
Avaliação da qualidade físico-química e microbiológica de salsichas do tipo hot dog na cidade de Mossoró, Rio Grande do Norte, Brasil
}

\author{
Evaluation of the physicochemical and microbiological quality of hot dog sausages in the city of \\ Mossoró, Rio Grande do Norte, Brazil \\ Evaluación de la calidad fisicoquímica y microbiológica de salchichas de hot dog en la ciudad de \\ Mossoró, Rio Grande do Norte, Brasil
}

\section{Resumo}

A salsicha é um embutido cárneo altamente comercializado e consumido pela população brasileira. Contudo, a alta manipulação durante o processamento aumenta os riscos de contaminação, sendo necessário a investigação da qualidade para verificar se o alimento está apto para o consumo humano. Assim, objetivou-se avaliar a qualidade físico-química e microbiológica de salsichas do tipo hot dog comercializadas no município de Mossoró, Rio Grande do Norte, Brasil. As amostras foram selecionadas e adquiridas em supermercados com venda à granel, sendo aferida a temperatura no ato da compra e transportadas ao laboratório em caixas isotérmicas para a realização das análises. Avaliou-se a temperatura, umidade, acidez e pH, bem como a qualidade microbiológica para coliformes totais, coliformes termotolerantes, Salmonella sp., bactérias mesófilas e bolores e leveduras. Verificou-se que $70 \%$ das amostras estavam com a temperatura acima do permitido para embutidos cárneos resfriados. Os valores encontrados nas análises de umidade, acidez e pH foram satisfatórios quando comparados à legislação vigente. Quanto às análises microbiológicas, $10 \%$ das salsichas apresentaram contagens de coliformes termotolerantes acima do valor de referência na Instrução Normativa vigente e em $20 \%$ constou a presença de Salmonella sp., o que torna tais amostras impróprias para o consumo humano, apresentando um risco em potencial à saúde pública. As amostras apresentaram contagens elevadas para bactérias aeróbias mesófilas e bolores e leveduras, podendo sugerir possíveis contaminações e condições de insalubridade durante o processamento. Assim, se faz necessário o emprego de boas práticas de manipulação, processamento e comercialização visando a melhoria na segurança e integridade desse produto. 
Palavras-chave: Doenças transmitidas por alimentos; Micro-organismos patogênicos; Micro-organismos deteriorantes; Produto cárneo; Saúde pública.

\begin{abstract}
Sausage is a meat sausage highly commercialized and consumed by the Brazilian population. However, high handling during processing increases the risk of contamination, requiring quality research to verify that the food is fit for human consumption. Thus, the objective was to evaluate the physical-chemical and microbiological quality of hot dog sausages sold in the city of Mossoró, Rio Grande do Norte, Brazil. The samples were selected and purchased in supermarkets with bulk sales, the temperature being measured at the time of purchase and transported to the laboratory in isothermal boxes for analysis. The temperature, humidity, acidity and $\mathrm{pH}$ were investigated, as well as the microbiological quality for total coliforms, thermotolerant coliforms, Salmonella sp, mesophilic bacteria and molds and yeasts. It was found that $70 \%$ of the samples had the temperature above the allowed for cold meat sausages. The values found in the analysis of moisture, acidity and $\mathrm{pH}$ were satisfactory when compared to current legislation. As for microbiological analyses, it was found that $10 \%$ of the sausages evaluated had counts of thermotolerant coliforms above the reference value in the current Normative Instruction and in $20 \%$ there was the presence of Salmonella sp, which makes such samples unfit for human consumption, presenting a potential risk public health. The samples showed high counts for aerobic mesophilic bacteria and molds and yeasts, which may suggest possible contamination and unhealthy conditions during processing. Thus, it is necessary to employ good practices in handling, processing and marketing in order to improve the safety and integrity of this product.
\end{abstract}

Keywords: Foodborne diseases; Pathogenic microorganisms; Deteriorating microorganisms; Meat product; Public health.

\title{
Resumen
}

La salchicha es un embutido cárnico altamente comercializado y consumido por la población brasileña. Sin embargo, su elevada manipulación durante el procesamiento aumenta los riesgos de contaminación, siendo necesaria la investigación de la calidad para verificar si el alimento está apto para el consumo humano. Así, el objetivo fue evaluar la calidad físico-química y microbiológica de salchichas del tipo hot dog comercializadas en el municipio de Mossoró, Rio Grande do Norte, Brasil. Las muestras fueron seleccionadas y compradas en supermercados con venta a granel, midiéndose la temperatura en el momento de la compra y transportándose al laboratorio en cajas isotérmicas para su análisis. Se investigó la temperatura, humedad, acidez y pH, así como la calidad microbiológica para coliformes totales, coliformes termotolerantes, Salmonella sp, bacterias mesófilas, mohos y levaduras. Se encontró que el $70 \%$ de las muestras tenían uma temperatura superior a la permitida para embutidos. Los valores encontrados en el análisis de humedad, acidez y $\mathrm{pH}$ fueron satisfactorios al compararlos con la legislación vigente. En cuanto a los análisis microbiológicos, se verificó que el $10 \%$ de las salchichas evaluadas presentaron recuentos de coliformes termotolerantes por encima del valor de referencia en la Instrucción Normativa vigente y en el $20 \%$ hubo presencia de Salmonella sp, lo que hace que tales muestras sean inapropiadas para el consumo humano, presentando un riesgo potencial para la salud pública. Las muestras presentaron recuentos elevados para bacterias aerobias mesófilas, mohos y levaduras, pudiendo sugerir posibles contaminaciones y condiciones de insalubridad durante el procesamiento. Por lo tanto, es necesario emplear buenas prácticas en el manejo, procesamiento y comercialización, con el fin de mejorar la seguridad e integridad de este producto.

Palabras clave: Enfermedades transmitidas por alimentos; Microorganismos patógenos; Microorganismos deteriorantes; Producto cárnico; Salud pública.

\section{Introdução}

Entende-se por salsicha o produto cárneo obtido através do processamento de um ou mais tipos de carnes e que são embutidas com envoltórios naturais ou artificiais (Brasil, 2000), sendo um alimento que apresenta alta aceitabilidade entre os consumidores, seja pelo sabor ou pela praticidade do preparo (García et al., 2010). Contudo, a alta atividade de água, os compostos pertinentes de sua formulação e a intensa manipulação, desde o processo de produção até o consumidor final, são fatores que podem contribuir diretamente para a contaminação microbiana, diminuindo a vida útil do produto e aumentando os riscos de Doenças Transmitidas por Alimentos (DTA) (Alfaro, 2012).

Estudo realizado por Silva et al. (2017), onde avaliaram diversas incoerências de supermercados em relação às normas estabelecidas pela Vigilância Sanitária e Ambiental, foi possível observar que os principais inconvenientes estão associados ao processo de produção do alimento, transporte, manipulação e estrutura física dos estabelecimentos que o comercializa. 
Tendo em vista a importância da qualidade higiênico-sanitária que os alimentos devem apresentar para que sejam consumidos com segurança, é indispensável que haja constante avaliação da qualidade microbiológica dos alimentos, principalmente no que diz respeito aos micro-organismos indicadores, como é o caso dos coliformes totais e termotolerantes, além de verificar a presença ou ausência de bactérias causadoras de doenças gastrointestinais graves, como a Salmonella sp. (Montezani et al., 2017). Apesar da legislação vigente sobre os padrões microbiológicos para alimentos no Brasil (Brasil, 2001) não estipular valores determinantes de bactérias aeróbias mesófilas, bolores e leveduras em salsichas, grande quantidade dessas bactérias pode indicar falhas relacionadas à insalubridade, além de que muitos fungos são produtores de micotoxinas que podem comprometer a saúde do consumidor (Franco; Landgraf, 2008).

Assim, há necessidade de verificar as boas práticas de manipulação de alimentos dentro dos padrões higiênicosanitários satisfatórios, sendo necessários estudos microbiológicos e físico-químicos que comprovem a biossegurança alimentar, garantindo um alimento de qualidade ao consumidor. Dessa forma, o presente estudo teve como objetivo avaliar a qualidade físico-química e microbiológica de salsichas do tipo hot dog na cidade de Mossoró, Rio Grande do Norte, Brasil.

\section{Metodologia}

O estudo consistiu em análises de salsichas comercializadas de forma à granel na cidade de Mossoró, Rio Grande do Norte. Entre os meses de abril e maio de 2018 foram coletadas dez amostras desse produto em diferentes estabelecimentos escolhidos ao acaso (uma amostra por estabelecimento). A aquisição das amostras foi realizada de forma similar à compra convencional do produto na forma a granel, onde solicitou-se em balcão aproximadamente $300 \mathrm{~g}$ de forma aleatória, independente da marca, sendo o produto solicitado como "salsicha do tipo hot dog".

No momento da compra, aferiu-se a temperatura superficial de cada salsicha com a utilização de termômetro infravermelho com mira à laser (marca Perdigão, vendida de forma à granel). As amostras (A1, A2, A3, A4, A5, A6, A7, A8, A9 e A10) foram transportadas em caixas isotérmicas ao laboratório para a realização das análises.

Realizaram-se as avaliações físico-químicas de temperatura, $\mathrm{pH}$, acidez titulável e umidade. Aferiu-se o pH das amostras com o potenciômetro digital (PHS-3E ${ }^{\circledR}$ ) e a acidez titulável foi determinada com solução de hidróxido de sódio $0,1 \mathrm{~N}$ e fenolftaleína 1\% como indicador ácido-base (Brasil, 1999; Instituto Adolfo Lutz, 2005). Calculou-se a umidade baseada segundo à Association of Official Analytical Chemists (AOAC, 2000), realizada pela diferença entre o peso inicial e final das amostras depois de submetidas à estufa de secagem a $105^{\circ} \mathrm{C}$ após 24 horas, com pesagens consecutivas até obtenção de peso constante, com valores expressos em porcentagem, levando em consideração os resultados estipulados aceitáveis pela legislação de 65\% de umidade (Brasil, 2000).

Para as avaliações microbiológicas pesaram-se $25 \mathrm{~g}$ de cada amostra com posterior homogeneização em $225 \mathrm{~mL}$ de água peptonada estéril a $1 \%$, onde realizaram-se diluições seriadas até que se obtivesse a diluição $10^{-6}$. Os micro-organismos investigados foram: coliformes totais a $36^{\circ} \mathrm{C}$ e coliformes termotolerantes à $45^{\circ} \mathrm{C}$ para determinação do Número Mais Provável (NMP) por grama de salsicha; presença ou ausência de Salmonella sp. através do cultivo em meios caldos e ágares de enriquecimento seletivo e provas bioquímicas; contagem de bactérias aeróbias mesófilas pela técnica de espalhamento em superfície em ágar Plate Count Agar (PCA); e por fim, bolores e leveduras cultivados em meio Batata Dextrose Agar (BDA) (Apha, 2001; Brasil, 2003; Silva et al., 2010).

\section{Resultados e Discussão}

A temperatura das amostras (Tabela 1) apresentou média de $6,94^{\circ} \mathrm{C}$, com valores entre $-0,2^{\circ} \mathrm{C}$ e $13,9^{\circ} \mathrm{C}$, onde é possível observar que 70\% das amostras coletadas estão em desacordo com a Portaria CVS 5, de 09 de abril de 2013 da Agência Nacional de Vigilância Sanitária (ANVISA), que regulamenta as temperaturas de refrigeração para alimentos 
perecíveis resfriados embutidos de até $4^{\circ} \mathrm{C}$ (ANVISA, 2013). A temperatura é um dos parâmetros extrínsecos que mais influencia no desenvolvimento dos micro-organismos nos alimentos, onde um dos métodos de conservação alimentar mais amplamente utilizados é a refrigeração (Lino; Lino, 2014) e as condições inadequadas de armazenamento, junto às más práticas de manipulação, podem contribuir diretamente para a proliferação de micro-organismos (Nascimento et al., 2014). Além disso, junto à temperatura, o tempo de armazenamento é outro fator extremamente relevante quanto à garantia de qualidade do alimento para o consumidor, tendo em vista que salsichas (produtos pertencentes ao grupo dos embutidos) tem um prazo de validadede três dias (ANVISA, 2013).

Tabela 1. Avaliações dos parâmetros físico-químicos de salsichas do tipo hot dog no município de Mossoró, RN, 2018.

\begin{tabular}{ccccc}
\hline Amostra & Temperatura $\left({ }^{\circ} \mathrm{C}\right)$ & Umidade $(\%)$ & Acidez $(\%)$ & $\mathrm{pH}$ \\
\hline A1 & 8,7 & 58,9 & 0,56 & 6,03 \\
A2 & 5,6 & 60 & 0,58 & 5,65 \\
A3 & 9,6 & 61,6 & 0,49 & 6,07 \\
A4 & 12,8 & 60,6 & 0,44 & 5,45 \\
A5 & 11,3 & 62,4 & 0,54 & 6,15 \\
A6 & 13,9 & 61 & 0,51 & 6,3 \\
A7 & $-0,6$ & 61,9 & 0,5 & 6,2 \\
A8 & $-0,2$ & 61,5 & 0,45 & 5,6 \\
A9 & 10,6 & 64,8 & 0,5 & 5,3 \\
A10 & $-2,3$ & 59,6 & 0,42 & 5,9 \\
\hline Média & 6,94 & 61,25 & 0,5 & 5,86 \\
\hline
\end{tabular}

Fonte: Autores.

O teor de umidade das amostras apresentou valor médio de $61,25 \%$, variando de $58,9 \%$ a $64,8 \%$, e, dessa forma, encontram-se dentro dos padrões estabelecidos pela legislação, que determina um valor máximo de $65 \%$ de umidade (Brasil, 2000). Dana et al. (2018) estudaram acerca da qualidade físico-química e microbiológica de salsichas comercializadas em supermercados na cidade de Joinville/SC e constataram-se que $80 \%$ das amostras analisadas também estavam em acordo com a Normativa $\mathrm{N}^{\circ}$ 4, de 31 de março de 2000 para a industrialização de produtos de origem animal, ao qual a salsicha está inserida (Brasil, 2000), ou seja, resultados próximos ao encontrados no presente trabalho. A umidade é uma análise de extrema importância no estudo dos alimentos, pois a disponibilidade de água está diretamente ligada ao possível desenvolvimento de micro-organismos e reações enzimáticas. Isso implica tanto nos parâmetros físico-químicos quanto microbiológicos, podendo comprometer a qualidade final do produto e ser um meio de disseminação de Doenças Transmitidas por Alimentos (Alfaro, 2012).

A acidez das amostras variou entre $0,42 \%$ e $0,58 \%$ e os valores de $\mathrm{pH}$ oscilaram entre 5,3 e 6,3, o que sugere uma leve acidez das salsichas. A variação de $\mathrm{pH}$ entre as amostras pode estar associada à própria formulação do produto. Durante o processamento, podem ser empregados aditivos antioxidantes e estabilizantes capazes de alterar o $\mathrm{pH}$ e impedir o desenvolvimento de micro-organismos (Lírio; Brito; Antunes, 2017). Além disso, a queda nos valores do pH pode estar relacionada à presença de bactérias láticas, micro-organismos deteriorantes facilmente encontrados em produtos cárneos e que liberam metabólitos responsáveis pela acidificação do meio (Hentges et al., 2016; Marco et al., 2018).

A média das amostras de $\mathrm{pH}$ do presente estudo foi de 5,86, o que diverge de estudos realizados por Dana et al. (2018), que encontrou resultados para análises de pH em salsichas em torno de 6,5. Embora não haja um valor de referência mínimo e máximo de pH para salsichas (Brasil, 2000), o aumento ou diminuição do pH de produtos cárneos pode ser 
influenciado pela presença de metabólitos microbianos, bem como compostos resultantes da decomposição de proteínas (Franco; Landgraf, 2008; Oliveira et al., 2017).

Os valores de coliformes totais e coliformes termotolerantes das amostras (Tabela 2) foram semelhantes e variaram de $<3$ a $1.100 \mathrm{NMP} / \mathrm{g}$, onde $90 \%$ das salsichas estudadas apresentaram resultados satisfatórios quanto ao estudo de coliformes a $45^{\circ} \mathrm{C}$ pela legislação vigente, que preconiza o valor aceitável de $10^{3} \mathrm{NMP} / \mathrm{g}$ de amostra (Brasil, 2001).

Tabela 2. Contagens de coliformes totais, coliformes termotolerantes, Salmonella sp., bactérias mesófilas e bolores e leveduras em salsichas do tipo hot dog comercializadas em Mossoró, RN, 2018.

\begin{tabular}{cccccc}
\hline Amostra & $\begin{array}{c}\text { Coliformes Totais } \\
(\text { NMP*/g) }\end{array}$ & $\begin{array}{c}\text { Coliformes } \\
\text { Termotolerantes } \\
(\text { NMP*/g) }\end{array}$ & $\begin{array}{c}\text { Salmonella sp. } \\
\left(\mathrm{A} / \mathrm{P}^{* *}\right)\end{array}$ & $\begin{array}{c}\text { Bactérias mesófilas } \\
(\text { log. UFC ***/g) }\end{array}$ & $\begin{array}{c}\text { Bolores e leveduras } \\
(\log . \text { UFC/g) }\end{array}$ \\
\hline A1 & 3,6 & 3,6 & $\mathrm{~A}$ & 3,3 & 4,41 \\
A2 & $<3,0$ & $<3,0$ & $\mathrm{P}$ & 4,17 & 3,92 \\
A3 & $<3,0$ & $<3,0$ & $\mathrm{~A}$ & 4,54 & 3,57 \\
A4 & 9,2 & 9,2 & $\mathrm{~A}$ & 4,83 & 3,07 \\
A5 & $<3,0$ & $<3,0$ & $\mathrm{~A}$ & 4,06 & 4,39 \\
A6 & $<3,0$ & $<3,0$ & $\mathrm{~A}$ & 3,63 & 3,78 \\
A7 & 240 & 240 & $\mathrm{P}$ & 4,79 & 3,18 \\
A8 & 23 & 23 & $\mathrm{~A}$ & 3,73 & 4,32 \\
A9 & 9,2 & 9,2 & $\mathrm{~A}$ & 4,3 & 3,23 \\
A10 & 1100 & 1100 & $\mathrm{~A}$ & 3,11 & - \\
\hline Brasil (2001) & - & $10^{3}$ & A & - & \\
\hline
\end{tabular}

*Número Mais Provável; **Ausência/Presença; ***Unidade Formadora de Colônia. Fonte: Autores.

Mesmo dentro da legislação a presença de coliformes indica que o processamento não foi realizado de forma higiênica. Sabe-se que os coliformes totais compõem os grupos de bactérias gram-negativas que não originam esporos e fermentam a lactose, produzindo ácido e gás à $35 / 37^{\circ} \mathrm{C}$ (Franco; Landgraf, 2008) e que sua presença em alimentos como a salsicha podem indicar condições higiênico-sanitárias insatisfatórias no processamento ou pós-processamento. Por outro lado, a amostra A10 está em desacordo com Instrução Normativa supracitada, uma vez que os coliformes termotolerantes podem indicar contaminação de origem fecal recente do produto, sendo possível a presença de patógenos intestinais, visto que a população desse grupo é constituída de uma alta proporção de E. Coli (Assis; Uchida, 2014). Os resultados corroboram com o trabalho realizado por Vogel et al. (2018), onde constatou-se contaminação por coliformes termotolerantes em parte das amostras de salsichas do tipo hot dog vendidas na forma a granel avaliadas no estudo.

A resolução RDC nº 12 de 2001 (Brasil, 2001) estabelece como parâmetro de qualidade microbiológica de produtos cárneos in natura a ausência de Salmonella sp. em $25 \mathrm{~g}$ de amostra. As bactérias pertencentes a este gênero são geralmente associadas à surtos e doenças transmitidas por alimentos, apresentando assim um risco em potencial à saúde pública (Martins et al., 2011). Dessa forma, dentre as 10 amostras de salsichas analisadas nesta pesquisa, duas amostras (20\%) apresentaram presença deste micro-organismo, demonstrando inadequação ao consumo. Contudo, Bruno, Santos e Rezende 2015) pesquisou a presença de Salmonella sp. em salsichas vendidas a granel e encontrou resultados divergentes, onde não foi possível constatar a presença deste micro-organismo em nenhuma das amostras avaliadas, o que sugere uma congruência com a legislação vigente (Brasil, 2001).

De acordo com Vogel et al. (2018) os micro-organismos mesófilos conseguem se desenvolver com temperaturas entre $10^{\circ} \mathrm{C}$ e $45^{\circ} \mathrm{C}$, sendo este o grupo principal associado à contaminação de alimentos de origem animal. Dessa forma, para a 
contagem de bactérias mesófilas foi possível observar uma variação de 3,11 a 4,83 log.UFC/g, e, embora não haja uma regulamentação na legislação para a quantidade máxima destes micro-organismos em salsichas (Brasil, 2001), a contagem desses agentes biológicos tem sido utilizada com indicador qualidade higiênico-sanitária dos alimentos, e que quando presente em uma alta proporção pode sugerir falhas durante a cadeia produtiva (Franco; Landgraf, 2008).

Para bolores e leveduras os resultados variaram entre 2,78 log.UFC/g e 4,41 log.UFC/g. Estes micro-organismos são considerados agentes deteriorantes e que podem se desenvolver facilmente em produtos cárneos devido às características inerentes desses produtos, como pH, alta atividade de água e composição de nutrientes (Vogel et al., 2018). Assim como as bactérias mesófilas investigadas no presente trabalho, a presença de grandes contagens de bolores e leveduras podem sugerir condições insatisfatórias do processamento, instrumentos insalubres utilizados para a comercialização, bem como o armazenamento inadequado do produto (Nascimento et al., 2014).

\section{Conclusão}

As salsichas avaliadas apresentaram parâmetros físico-químicos aceitáveis para a comercialização do produto. Os valores de pH, acidez e umidade encontravam-se de acordo com a legislação vigente, sendo de suma importância a investigação desses parâmetros a fim de garantir a qualidade do alimento para os consumidores.

A pesquisa de micro-organismos demonstrou condições higiênico-sanitárias insatisfatórias no processamento das salsichas. A comercialização de forma à granel pode ter sido um fator contribuinte para tais achados, pois é necessária uma atenção maior nas práticas de higiene dos equipamentos que armazenam o alimento, no manipulador do produto, como também nos instrumentos utilizados para cortar e embalar. É indispensável a avaliação intermitente em prol das normas estipuladas pela legislação vigente a fim de garantir os parâmetros adequados para comercialização e consumo de salsichas, diminuindo os riscos de disseminação de Doenças Transmitidas por Alimentos e garantindo um produto sadio para o consumidor.

\section{Referências}

Alfaro, A. T., Bau, T. R., \& Dias, C. A. (2012). Avaliação da qualidade química e microbiológica de salsichas tipo Viena. Revista Instituto Adolfo Lutz, 71 (1), 207-210.

Alves, E. M., Toledo, V. D. A. A. D., Marchini, L. C. et al. (2009). Presence of coliforms, molds and yeasts in organic honey samples of Africanized honeybees from Paraná River islands. Ciência Rural, 39 (7), 2222-2224.

Anvisa (2013). Regulamento técnico sobre boas práticas para estabelecimentos comerciais de alimentos e para serviços de alimentação. Diário Oficial do Estado de São Paulo.

AOAC (2000). Official methods of the Association of the Agricultural Chemists. Association of Official Analytical Chemists.

Apha - American Public Health Association (2001). Standard methods for the examination of water and wastewater. American Public Health Association.

Assis, L. L. R., \& Uchida, N. S. (2014). Análise da qualidade microbiológica de Hortaliças minimamente processadas comercializadas em campo mourão, PR. Brazilian Journal of Surgery and Clinical Research-BJSCR, 5 (3), 17-22.

Batista, F. V. B., \& Bezerra, V. M. (2015). Ocorrências de doenças transmitidas por alimentos no município de Vitória da Conquista, Bahia. Cadernos ESP, 9 (1), 27-34.

Brasil (1999). Instrução Normativa no 20 de 21 de julho de 1999. Oficializa os Métodos Analíticos FísicoQuímicos para Controle de Produtos Cárneos e seus Ingredientes - Sal e Salmoura. Diário Oficial [da] República Federativa do Brasil.

Brasil (2000). Instrução Normativa $N^{\circ} 4$, de 31 de março de 2000, Normativas acerca da industrialização de produtos de origem animal. Diário Oficial [da] República Federativa do Brasil.

Brasil (2001). Resolução $n^{\circ} 12$, de 02 de janeiro de 2001, Regulamento Técnico sobre Padrões Microbiológicos para Alimentos. Diário Oficial [da] República Federativa do Brasil.

Brasil (2003). Instrução Normativa $n^{\circ}$ 62, de 26 de agosto de 2003. Métodos Analíticos Oficiais para Análises Microbiológicas para Controle de Produtos de Origem Animal e Água. Diário Oficial [da] República Federativa do Brasil. 
Braun, C. L. K., de Oliveira, A. P., Pedro, F. G. G., et al. (2016). Physicochemical, microbiological and microscopic evaluation of artesanal rapaduras produced in Cuiabá, Mato Grosso, Brasil. Acta Scientiarum. 38, 407-413.

Bruno, B. T., Santos, L. A., \& Rezende, C. (2015). Pesquisa de bioindicadores em salsichas vendidas a granel em supermercados do Noroeste Paulista. Revista Uniara, 18 (1), 189-197.

Cardoso, A. L. S. P., \& Tessari, E. N. C. (2013). Salmonella enteritidis em aves e na saúde pública: revisão de literatura. Revista Eletrônica de Medicina Veterinária, 11 (21), 1-27.

Dana, E. C., Viana, L., Neumann, O. S, et al. 2018). Avaliação físico-químicas e microbiológica de salsichas adquiridas no comércio da cidade de Joinville/SC. Nutrição Brasil, 17 (2), 80-87.

Franco, B. D. G. M., \& Landgraf, M (2008). Microbiologia dos alimentos. Atheneu.

García, M., Díaz, R., Puerta, F., et al. (2010). Influence of chitosan addition on quality properties of vacuum-packaged pork sausages. Ciência e Tecnologia de Alimentos, 30 (2), 560-564.

Gonçalves, R. C., Faleiro, J. H., dos Santos, M N G., et al. (2016). Micro-organismos emergentes de importância em alimentos: uma revisão da literatura. SaBios: Revista de Saúde e Biologia, 11 (2), 71-83.

Hentges, D., Zart, N., Marmitt, L. G., et al. (2016). Concentrações de nitrito e nitrato em salsichas. Revista Brasileira em Promoção da Saúde, 29 (1), $27-33$.

Instituto Adolfo Lutz (2005). Métodos físico-químicos para análise de alimentos. Instituto Adolfo Lutz.

Lino, G. C. L., \& Lino, T. H. L. (2014). Congelamento e refrigeração. UTFPR.

Lírio, T. F., Brito, B. M. S., \& Antunes, W. L (2017). Avaliação dos níveis de nitrito em salsichas comercializadas na cidade de Macaé/RJ. Revista de Engenharias da Faculdade Salesiana, 6, 10-14.

Marco, I., Vogel, C., \& Morandin, G. C. (2018). Salsichas tipo hot dog: perfil microbiológico, isolamento e caracterização de bactérias ácido láticas (bal) com potencial antagonista. Revista CSBEA, 4 (1), 149-162.

Martins, L.L., Santos, I. F., Franco, R. M., et al. (2011). Determination of pH and activity water (aw) and relation between the with the bacteriological profile the samples bovine and chicken "hot dog" sausages that are vacuumed and retail commercialized and comes from supermarkets in Rio de Janeiro and Niterói RJ. Revista Brasileira de Ciência Veterinária, 18 (2), 92-96.

Montezani, E., Giuffrida, R., Andrade, R. A. P., et al. (2017). Isolamento de salmonella spp. e staphylococcus aureus em carne de frango e condições dos estabelecimentos comerciais no município de Tupã-SP. Colloq Vitae, 9 (2), 30-36.

Nascimento, K. D. O., Augusta, I. M., da Rocha Rodrigues, N., et al. (2014). Alimentos minimamente processados: uma tendência de mercado. Acta Tecnológica, 9 (1), 48-61.

Oliveira, M. S., Sousa, V. C., Oliveira, C. P., et al. (2017). Qualidade físico-química e microbiológica da carne moída de bovino em açougue. Revista Electrónica de Veterinaria, 18 (12), 1-13.

Pereira, W. R., \& Ferreira, L. C. (2016). Aspectos microbiológicos e físico-químicos da conservação de cagaita (Eugenia dysenterica DC) com aplicação de revestimento comestível. Caderno de Ciências Agrárias, 8 (2), 9-13.

Silva, N., Junqueira, V. C. A., Silveira, N. F. A., et al. (2010). Manual de métodos de análise microbiológica de alimentos e água. Varela.

Silva, A. S., Silva, I. M. M., Rebouças, L. T. et al. (2016). Análise parasitológica e microbiológica de hortaliças comercializadas no município de Santo Antônio de Jesus, Bahia (Brasil). Revista Visa em Debate, 4 (3), 77-85.

Silva, L. S. G. R., Silva, I. M. M., \& Silva, R. M. (2017). Principais inadequações de supermercados verificadas nas notificações emitidas pela Vigilância Sanitária e Ambiental. Magistra, 29 (1), 1-7.

Silva, G. B. P., \& Mikalouski, U. (2018). Pesquisa de presença de Salmonella spp. em cama de aviário no município de Arapongas-PR. Revista Terra \& Cultura: Cadernos de Ensino e Pesquisa, 66 (34), 1-10. 